\title{
DEMOCRACIA COMO ANTIUTOPIA ${ }^{1}$
}

\author{
Douglas Ferreira Barros ${ }^{2}$
}

Resumo: O objetivo do artigo é estudar concepções da democracia como uma antiutopia. Pretendemos observar o estatuto das relações estabelecidas entre cidadãos e o poder político para mostrar como estas versões rebaixam as expectativas quanto às promessas do bom governo ou das ficções políticas. Não se trata aqui de fazer o recenseamento das democracias contemporâneas. Pretendemos destacar duas acepções para diferenciá-las das ficções políticas ideais e dos modelos utópicos. Na democracia, a condução do poder político e a ordenação do todo social é demarcada por interrupções e desajustes constantes. Seja para negar a dominação desmedida do poder político sobre os cidadãos, seja para afirmar a pertinência dos conflitos, democracias como antiutopias se afastam do ideal de uma sociedade reconciliada e estática. As mudanças, os impasses e a superação de desafios não demarcam avanços necessários ou recuos definitivos. A sua trajetória histórica não descreve um percurso teleológico com vistas a atingir o bem superior. A passagem entre momentos históricos não ocorre como resultado de uma acumulação de resultados do passado que mira a transição para a redenção definitiva de mazelas políticas. Partimos da questão: em que sentido a democracia como forma de ordenamento social e de estrutura do poder político é um modelo antiutópico? Nossa hipótese é que as acepções mencionadas a seguir advogam em favor de um realismo filosófico político, apresentando a democracia como experiência política que demanda a constante indagação e reformulação acerca dos limites da liberdade dos cidadãos.

Palavras-chave: democracia - utopia - liberdade - não dominação - agonismo.

\section{Utopias e contemporaneidade política}

O objetivo do artigo é estudar a democracia como antiutopia. Claeys ${ }^{3}$ defende que é um desafio fornecer uma definição utilizável de utopia. ${ }^{4}$ Antes mesmo dos escritos de Platão

${ }^{1} \mathrm{O}$ artigo resulta de pesquisa financiada pela Fapesp, Processo: 10/08619-1, instituição à qual agradeço enormemente. A primeira versão do trabalho foi apresentada nas Jornadas organizadas pelo Grupo de Estudos Espinosanos da Universidade de São Paulo, entre 30-31/05 e 01/06/2012, na mesa redonda: "Democracia e Utopia". As partes que discutem a democracia segundo os modelos de Pettit e Mouffe foram debatidas no VII Colóquio Nacional de Filosofia da História, ocorrido na Universidade Federal de Sergipe e na Universidade de São Paulo, em maio de 2015, tendo como tema: "Tempo, história e sociedade", congresso em homenagem à Profa. Dra. Maria das Graças de Souza, a quem eu envio os meus mais sinceros agradecimentos ontem, hoje e sempre.

2 Douglas Ferreira Barros é professor de Filosofia e do corpo permanente do PPG em Ciências da Religião da PUC-Campinas, Campinas, Brasil. Coordenador do Grupos de Estudos Ética, política e religião: questões de fundamentação (CNPq). E-mail: douglasfbarros@gmail.com

${ }^{3}$ CLAEYS, Utopia, p. 12.

${ }^{4}$ Claeys argumenta que: "A amplitude do gênero é desconcertantemente grande, englobando: ideais positivos de sociedades muito melhoradas; seus opostos satíricos negativos, às vezes chamados de antiutopias ou distopias; vários mitos de paraíso, eras de ouro e 'ilhas abençoadas', e retratos de 
encontram-se referências ${ }^{5}$ sobre as benesses das sociedades perfeitas por comparação com aquelas povoadas por homens corrompidos e plenas de injustiça, sevícia e conflitos. Desde então e ainda no século XXI, alguns se indagam acerca da validade da ideia de sociedades pacificadas e reconciliadas, perguntam-se melancolicamente pelo fim das utopias. Os fracassos dos projetos socialistas de sociedade, defendeu Isaiah Berlin ${ }^{6}$, seriam motivo bastante para sufocar até a última chama revolucionária em favor de uma sociedade na qual os homens se reconciliariam com os seus desejos e diferenças, livre e plenamente. Mas não. Parece que teimamos em espelhar nossa esperança de mudanças nos modelos de bons governos, na segurança e na bonança dos exemplos utópicos. Pelo menos essa é a avaliação de Berlin acerca dos filósofos que se dedicam à defesa de modelos políticos de mudança total ou daqueles que investem na possibilidade de uma mudança completa no curso da história.

Formas ideais de ordenamento do poder, modelos perfeitos de cidade, experiências políticas em que os homens seriam igualados aos santos, sociedades perfeitamente reconciliadas, são temas que intrigaram os filósofos políticos desde a antiguidade clássica. Criações políticas em que os impasses e os equívocos, tragédias e derrotas foram pensados como ilustrações das experiências terrestres, demasiadamente humanas e próprias de seres passionais, movidos por desejos e interesses. Ficções porque exemplos não realizados, perfeitos, por isso utópicas, não-lugares, tais referências figuram em textos filosóficos até a modernidade. Ainda após iniciada a modernidade pós Revolução Francesa, filósofos vários mobilizaram ardentes argumentos para os vários flancos do espectro político -direita e esquerda-, tanto para afirmar a necessidade de tomarmos as utopias como ideal regulador das experiências políticas concretas, quanto para fixá-las como horizonte no qual os homens e seus projetos políticos falíveis e tortuosos deveriam se orientar.

Ao avaliar a nossa experiência política do século XX, o pensador liberal Isaiah Berlin estabeleceu os dois polos nos quais a discussão sobre as utopias se efetivou: de um lado, o desejo de superação das aflições do presente; de outro, tratou-se de puro exercício de nossa criação poética.

A ideia de uma sociedade perfeita é um sonho muito mais antigo, seja devido aos males do presente, que levam os homens a imaginar o que seria o mundo sem essas aflições - a imaginar um Estado ideal em que não exista miséria ou ambição, perigo ou pobreza, trabalho brutal, medo ou insegurança -, seja devido ao fato de essas utopias serem ficções deliberadamente satíricas, criadas com a intenção de se criticar o mundo real e lamentar a ação dos que controlam os regimes existentes ou a falta de ação dos que passivamente a

pessoas primitivas vivendo em um estado natural; robinsonadas [ficções de sobrevivência] ou naufrágios; viagens imaginárias para a Lua e outros pontos do espaço; e constituições planejadas, cidades-modelo e várias outras visões de melhora. Essa lista está bem longe de ser exaustiva, mas nos força a estreitar a extensão do uso do termo 'utopia' para evitar perder qualquer aplicação significativa dele" (2013, p. 12).

${ }^{5}$ CLAEYS, Utopia, pp. 16-27.

${ }^{6}$ BERLIN, Limites da Utopia. 
eles se submetem; ou talvez, ainda, por se tratar de simples exercícios de imaginação poética. ${ }^{7}$

Exercícios de imaginação ou simplesmente ficções satíricas, as utopias seriam na avaliação de Berlin a encarnação da desvalorização do mundo real com a promessa de um horizonte de superação das mazelas. Haveria, enfim, uma identidade entre todas elas: "A principal característica da maioria das utopias (ou talvez de todas) é o fato de serem estáticas" ". Por representarem a perfeição, "não há nenhuma necessidade de novidade e de mudança". Elas cristalizam ideais de natureza humana: "os homens têm uma certa natureza fixa e inalterável, certos objetivos universais, comuns, imutáveis. Uma vez alcançados esses objetivos, a natureza humana está plenamente realizada"”.

Não obstante o presente do qual fala Berlin nos tenha informado algo diferente, não haveria por que duvidar que todas as virtudes potenciais humanas se materializariam nesses contextos de plenitude, a saber,

Uma sociedade [que] vive em estado de pura harmonia, no qual todos os membros vivem em paz, amam uns aos outros, encontram-se livres de perigo físico, de carências de qualquer tipo, de frustração, desconhecem a violência ou a injustiça, vivem sob uma luz perpétua e uniforme, em um clima temperado, em meio a uma natureza infinitamente generosa. ${ }^{10}$

Todavia, a trajetória humana na história nos mostraria quanto há de equívoco em vislumbrarmos em tais cenários de perfeição os horizontes ideais de nossas ações. Berlin destaca que "existe algo de radicalmente errôneo na ideia de uma sociedade perfeita" ". Ele anota que tragédias várias havidas na história seriam fruto não apenas da eclosão de convulsões sociais, mas têm relação com a ideia de se criar sociedades perfeitas. Mesmo havendo uma profusão de utopias que, mesmo irrealizadas, supõem haver sociedades perfeitas, Estados pacificados, povos ideais, diferentes entre si e cada um deles corrigindo eventuais falhas detectadas nos outros modelos, nem mesmo essa divergência teria sido bastante desanimadora para descrermos da validade das utopias. Qual delas escolher? Qual poderá superar definitivamente os equívocos dos demais?

Berlin, liberal e crítico das utopias com origem no marxismo, também via com restrições as mudanças históricas assentadas em desejos de transformação política e social desde a Revolução Francesa. Os resultados que geraram o convencem de que, no século XX, os esforços empregados por tantos homens e mulheres para a edificação de uma sociedade purgada de imperfeições -a miséria material, a desigualdade, a opressão política- pertenciam mais à dimensão da imaginação poética dos revolucionários do que constituíam um projeto político consistente em termos teóricos e práticos. É fato que, no caso de Berlin, se tratava de uma sentença a mais no conjunto de seus juízos avaliando as revoluções socialistas

\footnotetext{
7 BERLIN, Limites da Utopia, p. 29.

8 BERLIN, Limites da Utopia, p. 29.

9 BERLIN, Limites da Utopia, p. 29.

10 BERLIN, Limites da Utopia, p. 29.

11 BERLIN, Limites da Utopia, p. 29.
} 
assentadas sobre os ideais igualitários. Teríamos que dar razão a Berlin quanto ao fato de que os teóricos e filósofos críticos da desigualdade e da injustiça amparam seus desejos de transformação social e política porque não suportam lidar com a aridez do presente? $\mathrm{O}$ próprio Berlin concordaria com a avaliação de que os descaminhos da história humana arrastam para o deserto do descrédito quaisquer ideais. Nem mesmo os modelos de sociedade do presente se igualam aos ideais utópicos.

\section{Democracia, política e antiutopia}

Philipe Pettit em On the people's terms - a Republican theory and Model of Democracy ${ }^{12}$ defende que a retomada recente do pensamento republicano é edificada sobre a "idéia de que há um ideal de estado a se promover - a liberdade entendida como não-dominação- que é tanto pessoalmente motivante quanto politicamente implementável" ${ }^{\prime 13}$. Ele destaca linhas a seguir que não se trataria aqui de apresentar um modelo estabelecido como ficção política, mas de um ideal factível. Algo bem menos etéreo do que aqueles ideais criticados por Berlin, muito distante de um discurso utópico entabulado pelos filósofos do início da modernidade. Mas, que diferença haveria entre os ideais revolucionários tão criticados por Berlin e a afirmação de Pettit de que os princípios republicanos constituem, no final das contas, um ideal de Estado? Se é ideal, o modelo republicano é visto como um princípio regulador, um fim verdadeiro. Todavia, antes que o ideal se realize, um caminho é traçado para que se o atinja: a efetivação da liberdade. Para Pettit, a liberdade neste sentido é

não somente um valor da vida, ou apenas a matéria que vale em última instância. Trata-se nesse caso meramente de que isto é uma boa porta de entrada, orientada para guiar os governos formados e sustentados pelo povo. Deixe que os governos cuidem da liberdade de seus cidadãos nesse sentido que isso os levará à garantia de um conjunto de outros bens e prosseguirá até que atinjam um nível plausível de contentamento. Isto os protegerá contra a divisão, a desordem, a regulação intrusiva e deverá provê-los em um nível satisfatório contra a miséria, a pobreza, o descontentamento e a desigualdade. ${ }^{14}$

A liberdade como guia ou a porta de entrada refere-se a um modelo de Estado. E neste modelo Pettit pretende que os cidadãos estejam não somente resguardados contra a dominação desmedida do Estado, mas que, legitimamente, eles se voltem para um conjunto de demandas "por controle popular sobre os governos: é, com efeito, uma forma distinta de democracia" "15. Claríssima no texto é a avaliação confiante num modelo de democracia republicana, promotor de certa pacificação e relativa segurança das sociedades livres. Do mesmo modo que fora legítima a suspeita de Berlin em relação a tantas outras utopias

\footnotetext{
12 PETTIT, On the people's terms.

13 PETTIT, On the people's terms, p. 3.

14 PETTIT, On the people's terms, p. 3.

15 PETTIT, On the people's terms, p. 3.
} 
revolucionárias, é legítimo perguntar: a democracia na qual os cidadãos são conduzidos por sua própria liberdade seria, no presente, o novo mito a seduzir os filósofos como Pettit?

Sabe-se com clareza o que produzem as sociedades democráticas atualmente em termos de liberdade para os cidadãos. Como não considerar a posição de Pettit um ideal com a mesma estatura de modelo inatingível, tal como em outros tempos o foram os modelos de sociedades perfeitas e reconciliadas socialistas criticadas por Berlin? Teria Pettit se deixado seduzir pela retórica da mitologia política e estabelecido a democracia republicana como um modelo plausível, mas mesmo assim um ideal? O problema aqui reside não especificamente na democracia, mas no fato de que ela talvez seja uma utopia de liberdade. Utopia que se poderia vislumbrar com mais nitidez recorrendo ao contraponto realista de Maquiavel e alguns de seus intérpretes. Vejamos por quê?

É quase senso comum entre os estudiosos de Maquiavel que nas obras do florentino encontramos um arsenal crítico demolidor de utopias. Entre os tantos que sustentam essa tese encontramos Berlin. Mas nenhum texto sobre esse tema é mais incisivo do que Política e História $^{16}$, quando Althusser avaliar a propriedade dos principados novos. Aqui ele joga luz sobre um dos pontos nevrálgicos do problema ao se perguntar sobre as dificuldades encaradas pelo príncipe novo: "Um Príncipe Novo que dará Forma Nova à matéria existente, que deverá partir da matéria existente, que deverá modelá-la" ${ }^{17}$. Quem é o príncipe novo? Que tarefas ele tem? O príncipe novo deverá engendrar uma nova forma política, mas ele o fará não a partir de uma condição de onisciência e onipotência de ação, mas “...a unidade nacional será feita com os homens como eles são, com a matéria italiana como ela é, a partir de sua realidade e de sua diversidade caótica" 18 .

A diversidade caótica destacada por Althusser é justamente o real a ser confrontado pelo governante: um contexto sobre o qual não exerce um domínio pleno, mas que tentará estabelecer uma forma, um limite possível no qual se inscreverão as ações e os interesses de todos os homens, não somente dos justos e dos que assentem em favor da autoridade estabelecida. Por isso Althusser destaca a particularidade da "matéria italiana", isto é, da história efetiva feita de homens tal como eles são "a partir de sua realidade e de sua diversidade caótica”, ele completa. Segundo as próprias palavras de Althusser, Maquiavel realiza a "não projeção de uma utopia sobre a matéria, mas procura a inserção do plano político na própria matéria, nas estruturas políticas existentes" ${ }^{19}$. Há, portanto, um negativo que constitui a forma. É um negativo da utopia, um vazio do ideal verdadeiro. A forma é, por assim dizer, uma ausência para o príncipe novo tanto quanto para os homens que nela se inserem. Não que o príncipe novo esteja paralisado, que o seu horizonte de ação seja o estado de apatia diante da complexidade da matéria histórica que o envolve. A dificuldade com a qual ele se depara é tamanha que nos dá a medida da importância e da premência de seu trabalho sobre a matéria que é informe: o povo e seu desejo; os grandes e o seu hábito de mandar. Isso não apenas porque a história sobre a qual age tal príncipe seja a difícil conjuntura da Itália. Para Althusser qualquer matéria histórica é também

16 ALTHUSSER, Política e História.

17 ALTHUSSER, Política e História, p. 216.

18 ALTHUSSER, Política e História, p. 216.

19 ALTHUSSER, Política e História, p. 217. 
estado puramente negativo, de importância generalizada dos pequenos Estados italianos, aquela situação de decadência geral (negativo absoluto no qual se acumulam todas as contradições: fraqueza dos Estados, ocupação estrangeira, devastações, etc., descritas na invocação final) é tal que impõe o plano de regeneração nacional, pela constituição de um Estado Novo, por um lado, mas ao mesmo tempo impossibilita ou quase conferir a esse processo um ponto de aplicação, um começo. A matéria, em seu conjunto, exige uma forma nova, mas a matéria está em tal desordem, é ela a tal ponto ausência de forma, contém em si tão pouco esboço, desenho dessa forma, o ponto central em que a forma poderia começar a nascer, que é impossível fixar de antemão na matéria o lugar de nascimento da forma. ${ }^{20}$

Como negação, a ausência da forma perfeita diante do príncipe novo é o grande desafio da política e do poder. Não se trata de pensar aqui que a criação da forma é a efetivação de um modelo de bom governo, mas é a introdução de um novo conteúdo, uma ação que inova a história mesma. Isso, ensina Maquiavel, é a destituição dos modelos ideais como horizontes a ser atingidos, fórmulas a ser imitadas. A advertência afasta o governante e o teórico da política da ilusão acerca do ato político cuja precisão e eficácia põe fim aos impasses, promove a reconciliação pacífica do povo, tal como prometem os modelos míticos do poder atacados por Berlin.

Destaca Althusser, a ação política é o exercício de um não saber sobre a história. Ele demarca a impossibilidade de que fixemos antecipadamente o lugar e o momento ideais de "nascimento da forma", assim como de que se estabeleçam regras prévias da ação do príncipe. Esse não saber da ação, impõe-nos, portanto, a limitação de afirmar algo sobre matéria da política previamente ao ato político. O limite de toda ação política é esse não saber que, em ato, nada mais é do que a ação do príncipe novo como uma "aspiração à forma", ou segundo o próprio Althusser, "a matéria é puro vazio de forma, pura espera informe. A matéria italiana é uma potência vazia, que espera de fora que uma forma lhe seja trazida e imposta". ${ }^{21}$

\section{Democracia e liberdade: antiutopias do presente?}

A democracia, em certa versão contemporânea, é a expressão da forma política como antiutopia. Não é o caso aqui fazermos o recenseamento das acepções da democracia moderna, após a revolução francesa. Interessa-nos apenas mostrar em que sentido versões dela se apresentam muito distantes daquela estabelecida por Berlin, que aproxima certas formulações filosóficas dos modelos como utopias irrealizáveis.

Pensar a democracia como antiutopia é posicionar essa forma de ordenamento político na esteira das filosofias políticas críticas das ficções. Trata-se de uma estratégia de pensar a política para além da dicotomia que separa o plano dos modelos teóricos e o plano

20 ALTHUSSER, Politica e História, p. 217.

21 ALTHUSSER, Política e História, p. 217. 
prático em que se dá a aplicação dos mesmos modelos. Pensar a cidade ou qualquer ordenamento político como sendo instituído exclusivamente segundo uma ordem de princípios teóricos condena a atividade política a ser guiada por prescrições da razão. Está pressuposta nessa priorização dos princípios sobre a prática a avaliação de que os ordenamentos sem o recurso prévio aos modelos estariam condenados à insuficiência, ao desajuste, à limitação, à destruição. ${ }^{22}$

Algumas filosofias políticas críticas das ficções políticas veem com bons olhos a avaliação de Espinosa na muito mencionada passagem de abertura do capítulo I do Tratado Político, segundo a qual os filósofos preferem louvar de "múltiplos modos uma natureza humana que não existe em parte alguma a fustigar com sentenças aquela que realmente existe. Com efeito, concebem os homens não como são, mas como gostariam que eles fossem" 23 . O resultado desse distanciamento não poderia ser outro que o de não conceberem nenhuma "política que possa ser posta em aplicação" 24 . Uma política concebida assim só poderia "instituir-se na utopia ou naquele século de ouro dos poetas, onde sem dúvida não seria minimamente necessária" 25 . Não é o caso aqui comentarmos a avaliação, não finalizada pelo filósofo, acerca da democracia. Mas importa a ênfase atribuída a essa restrição das concepções utópicas da política. Como, então, pensarmos uma forma política como antiutopia?

Maquiavel sustenta no capítulo IX de O Príncipe ${ }^{26}$ que em todas as cidades se observa uma divisão entre dois desejos: o dos pequenos - de não ser dominados pelos ricos; o dos ricos -de querer dominar os pequenos. A liberdade nasce, então, da oposição entre um e outro desejos. Entre os principados, a expressão da liberdade se dá quando os cidadãos exercem sem limites, ou nos limites dados pela lei, esse desejo de se opor àqueles que não compartilham do mesmo desejo. A referência de Maquiavel centra-se na observação realista, segundo a qual a condição de efetivação da liberdade se ampara tanto no desejo de não ser dominado quanto na permanência do conflito -entre os grandes e os pequenos-, que resulta da permanência desse desejo. A constatação maquiaveliana se ancora, entre outros aspectos, no desejo como condição para a produção da liberdade.

É pelo menos emblemático que essa constatação ampara em certo sentido versões bastante distintas acerca da democracia. Ao se perguntar sobre os elementos da liberdade contemporânea, Pettit ${ }^{27}$ busca defender a tese de uma democracia em contexto republicano. Nesses termos, os indivíduos devem poder desfrutar plenamente daquelas liberdades fundamentais ${ }^{28}$ sem quaisquer intromissões ou impedimentos do poder. Qualquer restrição tornaria, para esse autor, a influência dos indivíduos sobre o poder ou fragilizada ou, no pior

22 RODRIGUES, La comunidad o la interrupción de la palavra fundadora.

${ }^{23}$ ESPINOSA, Tratado Político, I, 1, p. 5.

${ }^{24}$ ESPINOSA, Tratado Politico, I, 1, p. 5.

${ }_{25}^{2}$ ESPINOSA, Tratado Politico, I, 1, pp. 5-6.

26 MAQUIAVEL, O Príncipe.

27 PETTIT, On the people's terms.

${ }^{28}$ De quais liberdades Pettit está falando: “...liberdade de expressão, de associação e de viajar, que são necessárias para que as pessoas possam se candidatar a um cargo, de se associar em partidos, promover suas políticas e se opor a outros partidos, incluindo o partido governante, com críticas antes e no momento das eleições" (PETTIT, On the people's terms, Kindle Edition, doravante KE: 4829). 
dos casos, inviabilizada. Seria preciso então permitir que os indivíduos pudessem desfrutar dessas liberdades plena e irrestritamente para que efetivamente experimentassem a democracia em ambiente republicano. Para tanto, ele se pergunta: "como abordar a discussão sobre a influência que o povo pode ter na política? Devo olhar para ideais utópicos, talvez fantasiosos, de como a influência popular pode se materializar?". ${ }^{29}$

A questão que remete a investigação da democracia aos modelos utópicos visa advertir para o fato de que a sua formulação busca ultrapassar as restrições estabelecidas por Berlin acerca dos modelos fictícios. Nesse sentido que Pettit nos fala de uma democracia como antiutopia: aquela na qual os cidadãos plenamente vivem as liberdades e interferem, vigiam, alteram o poder sem o medo de que sejam fustigados por ele. Como no texto de Maquiavel, os indivíduos devem se mover livres pelo desejo de não ser dominados e conduzidos. Ele afirma:

é apenas numa sociedade onde os indivíduos têm estas liberdades - e, diria eu, têm-nas no sentido republicano forte de escapar ao domínio- que eles podem esperar continuar a partilhar igualmente um sistema de influência independente sobre o governo. Que qualquer das liberdades seja cerceada e as perspectivas de influência igualmente acessível ou individualizada estarão em perigo imediato. Aqueles que estão expostos a qualquer possibilidade de verificação ou coerção em reação à fala livre, podem, por exemplo, não emitir a sua crítica a esta ou àquela proposta. A falta de sua intervenção não dará apoio à proposta por omissão, como poderia ter feito em vários contextos. Não importa qual seja o contexto, o silêncio das pessoas não comunicará nada, uma vez que isso poderá sempre refletir sua falta de liberdade.

Ora, se Pettit observa nessa formulação uma experiência factível -inclusive simula exemplos- sua intenção é a de apresentar a democracia como forma política antiutópica. Isso porque parecem lhe incomodar as observações de Berlin acerca do estatuto excessivamente abstrato dos modelos concebidos sem lastro histórico. A posição de Berlin incomoda tanto que inclusive as versões nada comprometidas com o liberalismo também procuram apresentar seus modelos alternativos. Referimo-nos aqui à proposta de Mouffe acerca da democracia agonística.

Em The Democratic Parado ${ }^{30}$, a democracia apresentada como modelo de modo algum regula com a ideia de uma forma irrealizável, utópica. Mouffe propõe, em acordo com Lefort, identificar a democracia moderna como forma de governo -soberania popular- e como estrutura simbólica na qual o governo democrático é exercido ${ }^{31}$. Nos termos de Mouffe, a democracia não pressupõe sociedades bem ordenadas, nem modelos bem acabados

\footnotetext{
29 PETTIT, On the people's terms, KE, 4542.

30 MOUFFE, The Democratic Paradox.

31 Mouffe explica: "A novidade da democracia moderna, o que a torna propriamente 'moderna', é que, com o advento da 'revolução democrática', emerge novamente o velho princípio democrático de que 'o poder deve ser exercido pelo povo', mas desta vez dentro de um quadro simbólico informado pelo discurso liberal, com sua forte ênfase no valor da liberdade individual e nos direitos humanos" (MOUFFE, The Democratic Paradox, p. 2).
} 
institucionais, que pressuporiam a melhor fruição da liberdade. O sentido antiutópico das democracias reside em que incorporam o conflito e a luta pela implementação de interesses e posições políticas antagônicos: a liberdade é a experiência da confrontação, mais do que entre opiniões, entre formas de vida. ${ }^{32}$

Em sua versão utópica, a forma democrática defendida por Rawls, avalia Mouffe, supõe que a sociedade bem ordenada elimine a luta democrática entre adversários, cidadãos que partilham os princípios liberal-democráticos e defendem interpretações "do significado de liberdade e igualdade e do tipo de relações sociais e instituições a que se devem aplicar" ${ }^{33}$. Completa a pensadora:

É por isso que na sua "utopia liberal" a legítima dissidência teria sido erradicada da esfera pública. Como ele foi levado a defender tal posição? Porque é que a sua concepção de democracia não deixa espaço para o confronto agonístico entre interpretações contestadas dos princípios democráticos-liberais comuns? A resposta está, creio eu, na sua concepção equivocada da política, que se reduz a uma mera atividade de alocação entre interesses concorrentes suscetíveis a uma solução racional. É por isso que ele pensa que os conflitos políticos podem ser eliminados graças a uma concepção de justiça que apela à ideia de vantagem racional dos indivíduos dentro dos limites estabelecidos pelo razoável. ${ }^{34}$

O que seria então essa concepção agonística antiutópica? Primeiro, a autora faz questão de ressaltar sua posição cética em relação aos resultados que propicia ao conjunto dos cidadãos o modelo democrático liberal, seja ele de matriz rawlsiana ou o das democracias deliberativas em sentido habermasiano, por assim $\operatorname{dizer}^{35}$. Segundo, seria inadequada a resposta de ambos Rawls e Habermas- porque insistiriam na substituição da "racionalidade média e razoabilidade" dominante por outra forma de racionalidade, uma forma 'deliberativa' e 'comunicacional' ${ }^{36}$. Desse modo, partindo do reconhecimento da "dimensão do político", Mouffe entende que a política consiste em "domesticar a hostilidade e em tentar desarmar o antagonismo potencial que existe nas relações humanas", porém sem que se exclua o conflito, ou se o anule pelas instituições, gerando em outras dimensões da ação política reações antidemocráticas como reflexos do recalque do interesse e o desejo de participação excluído. Ela afirma:

A política visa a criação da unidade num contexto de conflito e diversidade; está sempre preocupada com a criação de um "nós" pela determinação de um "eles". A novidade da política democrática não é a superação desta nossa/seu oposição - que é uma impossibilidade - mas a forma diferente

\footnotetext{
32 MOUFFE, The Democratic Paradox, p. 97.

33 MOUFFE, The Democratic Paradox, p. 30.

${ }^{34}$ MOUFFE, The Democratic Paradox, p. 30.

${ }^{35}$ MOUFFE, The Democratic Paradox, pp. 80, 86-87.

${ }_{36}$ MOUFFE, The Democratic Paradox, p. 95.
} 
como ela se estabelece. A questão crucial é estabelecer esta discriminação de uma forma compatível com a democracia pluralista. ${ }^{37}$

A introdução da categoria de adversário político torna mais complexa e radical, no sentido de mais abrangente, a noção de antagonismo e deve incorporar o agonismo. "Antagonismo é luta entre inimigos, enquanto que o agonismo é luta entre adversários". E completa que o 'pluralismo agonista' tem por objetivo transformar o "antagonismo em agonismo".

Isto requer a criação de canais através dos quais as paixões coletivas serão dadas formas de se expressar sobre questões que, ao mesmo tempo em que permitem possibilidades suficientes de identificação, não construirão o adversário como um inimigo, mas como um adversário. ${ }^{38}$

\section{Considerações finais: realismo, democracia e antiutopia}

Chamamos de realismo político contemporâneo essa concepção que insiste distanciar ou retirar a democracia das formulações utópicas sobre os governos, as sociedades e a política em sentido amplo. Tal posição reafirma a importância de se pensar a democracia segundo parâmetros de legitimidade e realização tensionadas pelas condicionantes históricas. Trata-se de reconhecer que os equívocos e as hesitações são constantemente experimentados por atores políticos em todos os níveis de participação pública.

As avaliações de Pettit a respeito dos detalhes procedimentais de uma concepção republicana denunciam a dificuldade de apresentação de um modelo de democracia não utópico, inclusive para os pensadores liberais ${ }^{39}$. As limitações características das utopias de esquerda, denunciadas por Berlin, produziram indagações e revelaram limites acerca dos modelos apresentados pelos pensadores liberais no século XX. Pelo menos podemos contatálo pela avaliação de Mouffe acerca de certos aspectos dos modelos da democracia de Rawls e de Habermas: ilações ficcionais. A intenção de Pettit, a nosso ver, reagindo a algumas dessas limitações observadas no contexto de sociedades democráticas contemporâneas foi apresentar uma concepção republicana da democracia na qual os cidadãos podem exercer uma influência "individualizada, incondicionada e eficaz" sobre os governos e as instituições políticas. Para tanto, ele insiste na importância de se viabilizar os canais de "influência popular contra os efeitos de distorção das pressões eleitorais e lobbies privados" ${ }^{40}$. Acolher tais dispositivos nos arranjos, estruturas e práticas atuais das democracias não parecia a Pettit experiências "totalmente inviáveis ou utópicas".

Mouffe, por sua vez, procura recuperar a dimensão agonística indissociável da própria condição do vir-a-ser democrático. Isto não tem a ver apenas com a manifestação do antagonismo como a opção resolvida do jogo democrático, mas de afirmar um agonismo, uma produção de legitimidade que supõe conflitos constantes, embates intermináveis e com

\footnotetext{
37 MOUFFE, The Democratic Paradox, p. 101.

38 MOUFFE, The Democratic Paradox, p. 103.

39 PET'TIT, On the people's terms, KE, 5807-8.

40 PETTIT, On the people's terms, KE, 5807-8.
} 
horizontes nada resolvidos e pacificados ao extremo. Isto requer a manutenção de canais através dos quais as paixões coletivas possam se expressar, e não o recalque destas em benefício de um consenso que, no final das contas, termina por excluir e eliminar aqueles que dissentem, os discordantes, os dissonantes ${ }^{41}$. O consenso produzido em acordo com princípios ético-políticos democráticos, defende Mouffe, existe quando produzido "através de interpretações conflitantes" e da confrontação agonística é que se produzem as diversas concepções de cidadania. Uma bem ordenada democracia para Mouffe seria aquela em que os cidadãos experimentam a liberdade nos acordos instáveis, resultados de embates acolhidos pelas instituições, sempre em transformação e confrontadas aos seus próprios impasses, hesitações e equívocos.

Claeys estreita o uso do termo utopia em seu estudo sobre as suas várias acepções para evitar que se percam as diferentes referências e aplicações atribuídas ao mesmo. Utilizamos aqui o termo antiutopia não como sinônimo de distopia ${ }^{42}$ - antípoda da utopia-, mas em um sentido mais largo, diferente do estudo de Claeys acerca das críticas à utopia. A antiutopia a que nos referimos diz respeito às noções intencionalmente realistas, aplicáveis e avaliadas em contextos históricos precisos, considerando-se inclusive que tangenciam com equívocos, derrotas, imperfeições. Versões da democracia como antiutopia, como as que apresentamos acima, nos fazem ver que impasses e limites históricos são comuns não somente aos modelos de sociedade pensados em favor da liberdade, tal como acusava Berlin. A liberdade além da não-dominação, também como desejo de dominar, influir no poder e se opor ao adversário político é uma experiência de poder ou uma forma de vida que nos cobra constantemente a posição do príncipe novo: fazer nascer uma ordem possível, ainda que instável, na matéria histórica disforme.

\section{DEMOCRACY AS ANTI-UTOPIA}

Abstract: The aim of the article is to study conceptions of democracy as anti-utopia. We intend to observe the state of relations established between citizens and the political power to show how these versions lower the expectations about the promises of good government or political fictions. It is not an intention of this article the enumeration of the distinct models of contemporary democracies. By highlighting two of them, we intend to differentiate them from the ideal political fictions and utopian models. In democracy, the conduction of political power and the ordering of the social order is characterized by constant interruptions and maladjustments. As a form of resistance to the domination of political power over citizens or assuming the pertinence of conflicts, the anti-utopian democracies move themselves away from the ideal of a reconciled and static society. In them, changes, deadlocks and the overcoming of challenges do not necessarily result in advances or definitive setbacks, which would correspond to a teleological path towards overcoming clashes or to an accumulation of results from the past aimed at the transition to the definitive redemption of political faults. We start from the following question: in what sense can democracy, as a form of social order and structure of political power, be considered an anti-utopian model? Our hypothesis is that the conceptions studied in the article advocate for a philosophical-political realism, presenting democracy as a political experience that demands the permanent creation of liberty.

Keywords: democracy - utopia - liberty - non domination - agonism.

${ }^{41}$ MOUFFE, The Democratic Paradox, p. 99.

${ }^{42}$ CLAEYS, Utopia, pp. 175-187. 


\section{REFERÊNCIAS BIBLIOGRÁFICAS}

ALTHUSSER, L. Política e História. - de Maquiavel e Marx. São Paulo: Martins Fontes, 2007.

BERLIN, I. Limites da Utopia - ensaios de história das ideias. São Paulo: Companhia das Letras, 1991.

CLAEYS, G. Utopia - a história de uma ideia. São Paulo: Edições SescSP, 2013.

ESPINOSA, B. Tratado Político. São Paulo: WMF Martins Fontes, 2009.

MAQUIAVEL, N. Tutte le Opere. Firenze: Sansoni, 1992.

MOUFFE, Ch. The Democratic Paradox. London: Verso, 2000.

PETTIT, P. On the people's terms - A Republican Theory and Model of Democracy. Cambridge: Cambridge University Press - Edição do Kindle, 2012.

RODRIGUES, L. La comunidad o la interrupción de la palavra fundadora. In.: Spinozaoctavo colóquio. Córdoba: Editorial Brujas, 2012. pp. 41-52. 